\title{
Ciencia ficción de hoy, ciencia de mañana: construir una vida
}

\author{
doi: 10.52749/fh.v2i3.3
}

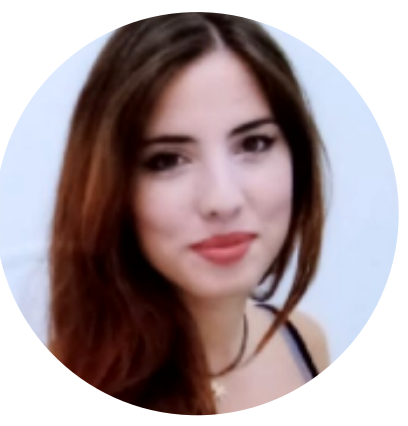

\section{CATERINA PRESUTTI ID https://orcid.org/0000-0003-0622-469X}

Magíster en Neurobiología y Bachiller en Biología por la Università La Sapienza de Roma, Italia. Actualmente estudia su PhD en Bioquímica, en Membrane Enzymology, del Departamento de Bioquímica de la Universidad de Groningen, Países Bajos, como parte del Marie Curie fellowship para el proyecto BiolnspireSensing (ITN-ETN).

\section{presutti.1676243@studenti.uniroma1.it}

Resumen. Cuando la ciencia ficción, el arte de la imaginación, se encuentra con la ciencia, se pueden crear cosas que antes parecían inimaginables. Es lo que sucede combinando fantasía y técnica, que hacen realidad proyectos imaginados y a veces sólo narrados en novelas, series de televisión o películas. Uno de los grandes sueños de los biólogos, de hecho, ya aparecido en una serie de televisión de ciencia ficción, es poder construir una vida, para poder entender no sólo cómo funciona sino también para tener posibles intuiciones sobre la vida en otros planetas. Este es el caso de un proyecto ambicioso en el que, utilizando los componentes moleculares de la biología, sería posible construir una célula sintética. En este artículo, partiendo del concepto de ciencia ficción y llegando a la conciencia de la sinergia que existe entre ciencia ficción y ciencia, se describirán algunos de los avances realizados hasta la fecha en la construcción de una vida celular, un tema que no sólo forma parte de la literatura de ciencia ficción, sino que, gracias a los avances científicos, se está convirtiendo cada vez más en realidad.

Palabras clave: biología, célula sintética, ciencia ficción

Ciencia ficción: utilizar ideas científicas como un truco para la imaginación. No es casualidad, en efecto, que las premisas para el nacimiento de la ciencia ficción se formaron a partir del siglo XVI con la revolución científica llevada a cabo por científicos como Galileo, Newton y Copérnico, aunque su nacimiento, propiamente dicho, fue el 5 de abril de 1926 con la publicación de la revista Amazing Stories de Hugo Gernsback. A partir de este énfasis en los detalles científicos se ha desarrollado una categoría de ciencia ficción llamada ciencia ficción tecnológica o hard science fiction, que ve en la exactitud científica y sus leyes el punto central para el desarrollo de la narración. Los nuevos descubrimientos en astronomía, física y biología se convierten en la inspiración de historias y relatos que tratan temas como la colonización del espacio, la vida en otros planetas, los viajes en el tiempo, la creación de sociedades utópicas o incluso la creación de un ser vivo. Sin embargo, la sinergia entre la ciencia y la ciencia ficción es tan fuerte que la ciencia ficción, a menudo, también se ha adelan- adelantado a la ciencia: "la ciencia ficción de hoy es a menudo la ciencia de mañana". Esto escribió Stephen Hawking en el libro "La Física de Star Trek" de Lawrence M. Krauss, acerca de las ideas científicas de la famosa serie Star Trek que luego se convirtieron en tecnologías y debates científicos actuales. En el libro menciona el replicator, cuyas funciones reproducen las impresoras 3D, y el teletransporte que ha dado lugar a preguntas sobre "la naturaleza de la realidad, el significado del yo, de la conciencia y de la individualidad".

Como ocurre a menudo, sobre todo en la ciencia ficción más moderna, no faltan referencias a la ingeniería genética, la bioquímica y la biología molecular, como para dar a la ciencia el enorme potencial de crear lo imposible, incluso lo que es sólo imaginación. Por ejemplo, en la miniserie de 1961 "A for Andrómeda" de la BBC, de la que también se ha hecho un remake en Italia de gran éxito, donde se habla del primer contacto con una raza alienígena y donde un ordenador electrónico construido y operado por el hombre utiliza la infor- 
mación de la tabla periódica, el ADN y los aminoácidos para crear la primera célula sintética. La serie anticipa temas que hoy en día son comunes, como la rápida evolución de las computadoras electrónicas, la exploración espacial y el sueño de los biólogos de sintetizar moléculas orgánicas y reproducir la vida en el laboratorio. Con el tiempo y el progreso científico, sin embargo, lo que una vez sólo se imaginaba en una novela, serie o historieta se vuelve cada vez más una realidad. No sólo por el avance en las nuevas tecnologías, sino, sobre todo, por cómo el Hombre se coloca en esta nueva realidad, recuperando la tarea de liderar el proceso evolutivo general y dirigiéndose hacia lo que llamaríamos Transhumanidad.

En 1957 Julian Huxley en su libro "New Bottles for New Wine", introdujo por primera vez el concepto de transhumanismo, "el hombre que sigue siendo humano, pero que trasciende a sí mismo, realizando las nuevas potencialidades de su naturaleza humana, para su naturaleza humana". En esta realidad actual, el sueño de los biólogos de la serie de ciencia ficción no está tan lejos: construir una célula sintética y luego una vida, para entender no sólo cómo funciona, sino también cómo nació. Las células sintéticas también podrían aportar ideas sobre cómo podría ser la vida en otros planetas. Este es uno de los objetivos llevados a cabo por la colaboración de varias universidades de los Países Bajos en el grupo Building a Synthetic Cell (BaSyC) en el ámbito de la llamada biología sintética, disciplina interesada en construir sistemas biológicos artificiales combinando conocimientos que van desde la química, la ingeniería genética y la bioinformática. La idea es utilizar los componentes moleculares de la biología para construir células a partir de cero, teniendo siempre en cuenta al menos cuatro aspectos esenciales: la compartimentación de las biomoléculas en el espacio, el metabolismo energético que sostiene la vida, el almacenamiento y la gestión de las instrucciones celulares dictadas por el ADN y la capacidad de reproducirse y dividirse (Powell, 2018).

\section{Los avances hasta la fecha}

Es importante tener en cuenta que la vida, en sí misma, es por definición un sistema de noequilibrio, es decir, donde las transiciones hacia adelante y hacia atrás no están equilibradas entre dos estados, sino que las transiciones son irreversibles. Básicamente, las reacciones de un sis- tema al desequilibrio, como la vida, continúan porque continuamente se suministran nutrientes y energía y se drenan los productos. Un sistema biológico cercano al equilibrio es un sistema muerto en sí mismo. Por lo tanto, es fundamental en la síntesis de una célula viva reconstruir un sistema lejos del equilibrio como la vida.

Pero si los ladrillos básicos para construir una célula, como los lípidos, los aminoácidos y los azúcares, se pueden encontrar fácilmente, ¿cómo llegaron a la Tierra para dar origen al comienzo de la vida celular? La primera respuesta fue en 1953 del químico Stanley Miller y el premio Nobel Harold Urey, quienes trataron de demostrar la hipótesis de Oparin-Haldane de que las condiciones de la Tierra primitiva habían favorecido reacciones químicas que conducían a la formación de compuestos orgánicos a partir de moléculas inorgánicas. Asumieron que en la atmósfera terrestre sólo se podía encontrar agua $(\mathrm{H} 2 \mathrm{O})$, hidrógeno $(\mathrm{H} 2)$, nitrógeno (N2), amoníaco (NH3), monóxido de carbono (CO), metano $(\mathrm{CH} 4)$ y ácido sulfhídrico $(\mathrm{H} 2 \mathrm{~S})$, liberados hace 4 mil millones de años por las erupciones volcánicas. Introdujeron metano, amoníaco, hidrógeno y agua en un globo de vidrio y lo bombardearon con descargas eléctricas que simulaban las cataratas de rayos que invadían la Tierra. Al final del experimento, había en el matraz, además de las moléculas iniciales, cinco aminoácidos diferentes y una variedad de compuestos orgánicos, incluyendo moléculas como el formaldehído (O-CH2) (Lazcano \& Bada, 2003). Aunque el experimento de Miller-Urey tiene una serie de limitaciones, incluyendo la distribución racémica 1:1 entre los aminoácidos levogiros y detrugiros, el resultado fue sin duda revolucionario y dio inicio a una serie de experimentos, incluyendo el de Joan Orò en 1961 que partiendo de ácido cianhídrico y amoníaco acuoso sintetizó la adenina, una base nucleotídica involucrada en la síntesis de ADN (Oró, 1960).

La idea es que, en el momento en que las moléculas orgánicas fueron creadas, los ladrillos fueron puestos a disposición para construir la vida celular. En particular, los lípidos se convirtieron en los componentes de las membranas celulares, los aminoácidos para las proteínas y los azúcares como parte integrante de los ácidos nucleicos. También se ha demostrado que las interacciones de los ácidos grasos de cadena única con la superficie de diferentes minerales dan lugar a una organización espontánea de las vesículas y membranas (Hanczyc et al., 2007). Este efecto podría haber desempeñado un papel clave en 
la organización y formación de las primeras estructuras parecidas a células, y es interesante que los minerales podrían estar involucrados en la formación de uno de los componentes esenciales de la vida celular, la membrana celular. Partiendo de la necesidad de reconstruir una membrana que separe el microambiente celular del exterior, la primera etapa en la construcción de una célula sintética es la elección del andamio. Por lo tanto, se pueden utilizar diferentes modelos, pero el que más se parece a las células naturales es el liposoma, una vesícula acuosa encapsulada por una capa doble de fosfolípidos. Al ser biocompatible, se puede integrar más fácilmente con otros componentes, como proteínas de membrana y polisacáridos (Abil \& Danelon, 2020).

Una vez construido el andamio, es necesario insertar todos los componentes necesarios para el funcionamiento y la supervivencia de la célula.

El laboratorio de Bert Poolman ha demostrado que el uso de proteínas de membrana insertadas en la capa doble de fosfolípidos, como el antiportador arginina/ornitina, que facilita la entrada de arginina (sustrato) en la célula y la salida de la ornitina (producto) en el exterior, garantiza la producción de ATP y mantiene lejos del equilibrio, garantizando así la energía para sostener la vida (Pols et al., 2019). En la célula, de hecho, la conversión de la arginina en ornitina, amoníaco y dióxido de carbono produce ATP en tres pasos enzimáticos. Además, dado que el crecimiento celular se ve afectado por la concentración de solutos del entorno, es esencial controlar el flujo de solutos en la célula para mantener el volumen constante y lograr la homeostasis. Para ello, la energía producida por la vía de degradación del ATP se utilizó para modular el equilibrio de los osmolitos en las vesículas mediante la activación del transportador de glicina betaína OpuA, un sensor de fuerza iónica que se activa en condiciones de deshidratación, favoreciendo la cantidad de glicina betaína y, por tanto, la reabsorción de agua por las células (Patzlaff et al., 2003).

\section{Conclusión}

Así que, trabajando como la Naturaleza ya ha hecho, y actuando sobre los diferentes aspectos que he mencionado antes, sería posible sintetizar en un laboratorio una célula autónoma y comprender no sólo los mecanismos moleculares de la vida, sino también utilizar este sistema como modelo para entender las patologías a nivel celular, para usarlas como fábricas químicas involucradas en la química verde y tener intuiciones sobre la presencia de vida en otros Planetas. En vista de los avances que se han hecho y se siguen haciendo en este campo, que una vez se representaban en una serie de ciencia ficción, surge la pregunta: ¿Cuánto de la ciencia ficción de ayer será la investigación de mañana? Tal vez la ciencia y la ciencia ficción siempre estarán en sintonía, y como escribió el innovador autor de ciencia ficción Ray Bradbury: "La ciencia ficción es cualquier idea que se te ocurra que aún no existe, pero pronto existirá y cambiará todo para todos y nada será como antes. Tan pronto como se te ocurre una idea que cambia una pequeña parte del mundo, estás escribiendo ciencia ficción. Es siempre el arte de lo posible, nunca de lo imposible". Y yo añadiría que es precisamente la ciencia la que la hace realidad, este arte de lo posible que narra pensamientos e ideas a los que, tal vez, estamos cada vez más cerca. 


\section{Referencias}

Abil, Z., \& Danelon, C. (2020). Roadmap to Building a Cell: An Evolutionary Approach. Frontiers in Bioengineering and Biotechnology, 8, 927. https://doi.org/10.3389/fbioe.2020.00927

Hanczyc, M. M., Mansy, S. S., \& Szostak, J. W. (2007). Mineral surface directed membrane assembly. Origins of Life and Evolution of Biospheres, 37(1), 67-82. https://doi. org/10.1007/s11084-006-9018-5

Lazcano, A., \& Bada, J. L. (2003). The 1953 Stanley L. Miller experiment: fifty years of prebiotic organic chemistry. Origins of Life and Evolution of the Biosphere, 33(3), 235-242. https://doi.org/10.1023/A:1024807125069
Oró, J. (1960). Synthesis of adenine from ammonium cyanide. Biochemical and Biophysical Research Communications, 2(6), 407-412. https://doi.org/10.1016/0006-291X(60)90138-8

Patzlaff, J. S., van der Heide, T., \& Poolman, B. (2003). The ATP/substrate stoichiometry of the ATP-binding cassette (ABC) transporter OpuA. Journal of Biological Chemistry, 278(32), 29546-29551. https://doi.org/10.1074/jbc.M304796200

Pols, T., Sikkema, H. R., Gaastra, B. F., Frallicciardi, J., Śmigiel, W. M., Singh, S., \& Poolman, B. (2019). A synthetic metabolic network for physicochemical homeostasis. Nature communications, 10(1), 1-13. https://doi.org/10.1038/s41467019-12287-2

Powell, K. (2018). How biologists are creating life-like cells from scratch. Nature, 563, 172-175. http://protobiology.org/wp3/wp-

- $\quad$ content/uploads/2018/11/nature synbiosyntheticcelldesigns.pdf

\section{Cómo citar este artículo:}

Presutti, C. (2021). El transhumanismo: el triunfo del culturalismo y el fin de la selección natural. Futuro Hoy, 2(3), 20-23. https://doi.org/10.52749/fh.v2i3.3 